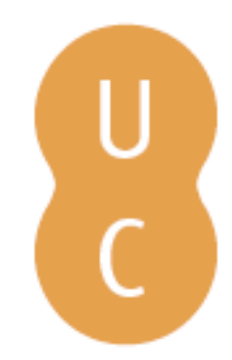

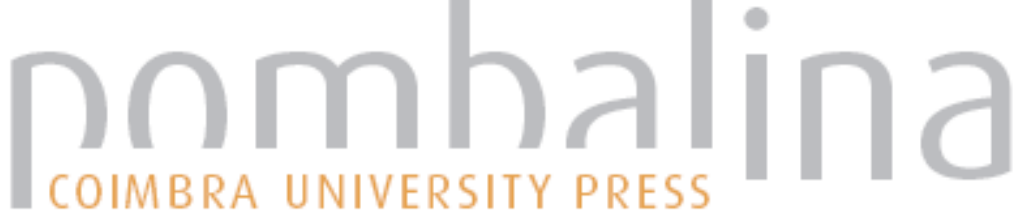

\section{A evolução da política externa da Rússia}

Autor(es): $\quad$ Freire, Maria Raquel

Publicado por: Imprensa da Universidade de Coimbra

URL

persistente:

URI:http://hdl.handle.net/10316.2/31895

DOI:

DOl:http://dx.doi.org/10.14195/978-989-26-0712-2_1

Accessed : $\quad$ 26-Apr-2023 13:51:58

A navegação consulta e descarregamento dos títulos inseridos nas Bibliotecas Digitais UC Digitalis, UC Pombalina e UC Impactum, pressupõem a aceitação plena e sem reservas dos Termos e Condições de Uso destas Bibliotecas Digitais, disponíveis em https://digitalis.uc.pt/pt-pt/termos.

Conforme exposto nos referidos Termos e Condições de Uso, o descarregamento de títulos de acesso restrito requer uma licença válida de autorização devendo o utilizador aceder ao(s) documento(s) a partir de um endereço de IP da instituição detentora da supramencionada licença.

Ao utilizador é apenas permitido o descarregamento para uso pessoal, pelo que o emprego do(s) título(s) descarregado(s) para outro fim, designadamente comercial, carece de autorização do respetivo autor ou editor da obra.

Na medida em que todas as obras da UC Digitalis se encontram protegidas pelo Código do Direito de Autor e Direitos Conexos e demais legislação aplicável, toda a cópia, parcial ou total, deste documento, nos casos em que é legalmente admitida, deverá conter ou fazer-se acompanhar por este aviso.

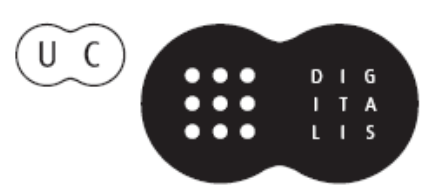


IMPRENSA DA

UNIVERSIDADE

DE COIMBRA

COIMBRA

UNIVERSITY

PRESS

\section{A POLÍTICA EXTERNA \\ RUSSA NO ESPAÇO \\ EURO-ATLÂNTICO}

$\therefore:$

\section{Dinâmicas de cooperaçấo e}

competiçẫo num espaço alargado

PÁTRICIA DAEHNHARDT

MARIA RAQUEL FREIRE

Coordenadoras 
(Página deixada propositadamente em branco) 


\section{CA P ÍTULO 1}

\section{A EVOLUÇÃO DA POLÍTICA EXTERNA DA RÚSSIA}

Maria Raquel Freire

O final da Guerra Fria e a desagregação da União das Repúblicas Socialistas Soviéticas (URSS) em 1991 constitui um marco histórico fundamental, com consequências a vários níveis. A nível político representa o fim do grande bloco de leste que marcou a rivalidade bipolar no confronto com o bloco ocidental. Após décadas de bipolaridade a redefinição da ordem internacional implicada nestes acontecimentos constitui um desafio a longo prazo. O lugar da Federação Russa no sistema internacional, após assumir responsabilidades fundamentais da antiga URSS, como, por exemplo, o assento permanente no Conselho de Segurança das Nações Unidas (CSNU), assume relevância no entendimento de possíveis configurações desta nova ordem. A questão do ajuste necessário entre a extinta superpotência URSS e a sua sucessora fragilizada, destaca-se na agenda internacional.

O fim do bloco soviético representou também o falhanço de um modelo de governação assente na ideologia marxista-leninista, cuja experimentação desvirtuou os pressupostos de base, gerando disparidade, iniquidade, e por vezes tendendo ao conformismo acrítico perante um conjunto de princípios e procedimentos definidos pela elite dirigente do Partido Comunista. Em termos sociais, esta experimentação revelou constrangimentos vários ao nível da expressão de liberdades individuais, apontando o caminho da coletivização como o caminho para o desenvolvimento e crescimento. A centralização do poder político e o sistema fechado em que a política se fazia não permitia uma relação de proximidade entre 
os dirigentes e a população em geral. A nível económico, as políticas de coletivização, os planos de desenvolvimento e produtividade centrados na indústria pesada, num contexto de Guerra Fria, criaram obstáculos variados à promoção de um desenvolvimento horizontal, com investimento em setores diferenciados da economia e que acabou por se refletir nas outras dimensões de atividade, nomeadamente política e social.

O processo de transição que se inicia com o fim da União Soviética, para além de significar uma reestruturação profunda de um sistema centralizado de orientação comunista, para um novo quadro político, económico e social, significou ainda o redimensionamento da Rússia, num novo mapa geográfico onde a antiga União Soviética deu lugar a 15 novos Estados, incluindo a Federação Russa. O impacto desta alteração geopolítica é significativo, apesar de a Rússia ter mantido os lugares de representação nas principais organizações internacionais, incluindo um lugar permanente no CSNU, bem como capacidade nuclear. Neste contexto, este capítulo analisa a política externa russa em transição, desde o final da Guerra Fria e da União Soviética até aos nossos dias, visando compreender as dinâmicas de reformulação de políticas e práticas que vem sendo operacionalizada num contexto diferenciado.

O capítulo começa com a contextualização do processo de transição, sublinhando o modelo de governação interno e o reajustamento político que a Rússia vai prosseguir. A análise da experiência democrática na Rússia pós-soviética será objeto de atenção, bem como as implicações associadas à transição política e social, e o regresso ao centralismo. Além do mais, as relações que a Rússia desenvolve na sua área de vizinhança, e como a sua política se molda aos desenvolvimentos que aí têm lugar, serão ainda analisadas. O texto prossegue com o enquadramento da transição russa no contexto internacional em que esta tem lugar. Em particular serão analisadas aqui as relações a ocidente, incluindo os Estados Unidos da América (EUA) e a União Europeia (UE), e na sua dimensão oriental, a China. Sem pretender desenvolver uma análise exaustiva, o capítulo procura ilustrar a evolução da política externa russa, nas suas linhas de continuidade e mudança e nos vários palcos em que esta se desenvolve. 


\section{Transição do modelo soviético: a experiência democrática}

A Rússia dos czares e a União Soviética representam séculos de governação centralizada onde as linhas definidoras de democracia, num entendimento amplo do conceito, incluindo não só a participação popular em atos eleitorais, mas também questões de representatividade, direitos e liberdades individuais, nunca estiveram presentes. Deste modo, o final da União Soviética gerou um breve período onde na transição para um novo desenho político, o processo de democratização foi equacionado mas nunca verdadeiramente implementado, com a política de abertura iniciada por Mikhail Gorbachov rapidamente a dar lugar a tendências de centralização e controlo, pouco após Boris Ieltsin assumir a presidência. Vários factores contribuíram para este desenvolvimento, incluindo a falta de experiência democrática e a instabilidade que as medidas a serem implementadas acabaram por gerar. De facto, as reformas promovidas tiveram um impacto muito claro na vivência quotidiana das populações, que se viram privadas de um conjunto de bens anteriormente assegurados pelo Estado, como por exemplo transportes públicos ou eletricidade gratuita. No contexto de transição capitalista estes pressupostos são suprimidos em favor de princípios de iniciativa privada, numa sociedade que não os reconhecia. Daí o surgimento de uma nova classe social - os oligarcas -, como analisado adiante, que reflete um número restrito de pessoas que passam a deter bens fundamentais anteriormente propriedade do Estado, em processos de privatização pouco transparentes.

A adicionar à parca clareza das dinâmicas em curso, a organização de processos eleitorais ditos democráticos é também ela exterior à realidade vivida ao longo de várias décadas. Os processos democráticos implicam não só mudanças profundas de procedimentos e mentalidades, como também tempo para que a sua solidez se possa concretizar e manifestar no quotidiano político e socioeconómico. Neste quadro, e dadas as dificuldades associadas ao processo de transição na Rússia, que se acabou por revelar uma transição incompleta, é uma interpretação minimalista de democracia, centrada na realização de eleições (independentemente da qualidade dos processos eleitorais) a que perdura até aos dias de 
hoje. Uma transição que está por acabar, e que se tem materializado num modelo de governação com traços autoritários e de centralização de poder, a par de uma política de abertura ao exterior e modernização interna - factores que não são facilmente conciliáveis.

A política externa russa tem evoluído de acordo com ajustes internos resultantes do próprio processo de transição, e com o contexto internacional em que se tem desenvolvido. É aqui assumido que as dinâmicas de política externa não podem ser dissociadas da componente funcional interna ao Estado, onde os processos de formulação, decisão e implementação de políticas têm lugar, associados a variáveis concretas em termos de objetivos e meios para a sua prossecução. Vários autores têm avançado com tipologias caracterizadoras da evolução da política externa russa, que ajudam o leitor a situar dinâmicas e atores. Neste trabalho seguiremos a proposta de Richard Sakwa (2012), que propõe quatro fases na análise da evolução da política externa russa: internacionalismo liberal, competitividade pragmática, novo realismo e neo-revisionismo. Segundo este autor, a primeira fase que se situa no período pós-independência onde se começam a desenhar objetivos contraditórios de integração em estruturas ocidentais, enquanto prosseguindo o estatuto de grande potência com uma vertente centralizadora clara, denomina-se de 'internacionalismo liberal'. Este período ficou marcado pela viragem e abertura a ocidente da política russa assente no discurso promovido por Gorbachov sobre a 'casa comum Europeia' e prosseguido por Ieltsin e o ministro dos negócios estrangeiros Andrei Kozyrev.

Nesta fase a Rússia reforça relações com as Comunidades Europeias, adere à Parceria para a Paz no âmbito da Organização do Tratado do Atlântico Norte (OTAN) e solicita a sua adesão ao Conselho da Europa. No entanto, os benefícios esperados do apoio ocidental e as políticas de condicionalidade associadas à pertença a estas instituições não correspondem às necessidades do processo de transição russo, especialmente em termos económicos, o que acaba por levar à formulação de críticas severas dentro do sistema, especialmente dos grupos mais conservadores. A resposta a esta surge na adoção de uma visão mais estratégica em termos de uma atuação mais ativa na vizinhança próxima, que havia 
sido de algum modo descurada no processo em curso, em detrimento da política de aproximação ao ocidente.

No entanto, a alteração no discurso não foi suficiente para evitar uma alteração neste alinhamento pró-ocidental. Apesar da relevância que a Comunidade de Estados Independentes (CEI) assume na agenda de política externa, o desequilíbrio associado à dimensão ocidental necessitava de ser corrigido. A pressão para a mudança de orientação da política externa russa vai resultar no início de uma nova fase, identificada como de 'competitividade pragmática' e associada à chegada ao Ministério dos Negócios Estrangeiros de Evgeny Primakov, em janeiro de 1996. Com uma visão mais crítica do ocidente, embora assumindo uma postura de cooperação, adiciona à política externa russa a necessidade de desenvolvimento de relações com a China, a Índia e o Médio Oriente. Desta forma, Primakov pretendia maior equilíbrio na política externa russa, o que lhe permitia maior margem de manobra em termos negociais nestas várias dimensões de atuação. Além do mais, este reajuste possibilitava reafirmar uma questão que foi desde o início do processo de transição fundamental para as políticas da Federação Russa - uma ordem internacional multipolar. Primakov assume uma política pragmática, mas também competitiva, no sentido em que se define em 'competição' com o ocidente, não num sentido tradicional militar de Guerra Fria, mas em termos do reconhecimento do estatuto da Federação Russa como ator privilegiado no sistema internacional. Igor Ivanov, a partir de 1999 na pasta dos Negócios Estrangeiros, dá continuidade ao pragmatismo do seu antecessor, mantendo na sua essência os alinhamentos da política externa russa.

O ano 2000 constitui um ano de viragem, após a retirada anunciada de Ieltsin e a chegada ao poder de Vladimir Putin. Eleito presidente da Rússia na primavera desse ano, Putin incute um 'novo realismo' à política externa russa, que o ministro dos negócios estrangeiros Igor Ivanov acompanha. Este traduz-se na combinação de uma visão tradicional realista de interesse nacional e de prossecução do mesmo no sistema internacional, com a procura de equilíbrios e vantagens competitivas para a Rússia, com particular ênfase para as estruturas ocidentais e as Nações Unidas. Este duplo processo de socialização e adaptação 
enquanto mantendo uma política externa independente procurava dar resposta às ambivalências que as anteriores políticas haviam produzido, especialmente visíveis na tensão permanente entre a escolha de uma aproximação ao ocidente que a ala europeísta defendia, de um maior diálogo a oriente promovido pelos orientalistas, ou de concentração no espaço vital, com base em pressupostos nacionalistas. Estas tensões não desapareceram, mas Putin através das suas políticas, assentes num pressuposto de multivetorialidade bem delineado, consegue introduzir uma maior coerência na política externa russa. É importante sublinhar que a política multivetorial não foi uma novidade introduzida por Putin, antes refletia a consolidação de um processo que havia sido iniciado ainda na presidência de Ieltsin, como analisado, e que se sintetiza na priorização geoestratégica no que são denominados vetores de política externa: a CEI como área de atuação prioritária, seguida dos vetores ocidental e oriental. Contudo, o contexto era então de grande instabilidade no espaço pós-soviético, e as contradições inerentes aos processos de desenvolvimento de 'parcerias estratégicas' com os EUA e a UE não permitiram que as contradições sugeridas por este posicionamento fossem facilmente ultrapassadas.

A adicionar às dinâmicas internas, o contexto internacional revelou-se difícil para o prosseguimento das políticas de reafirmação russas, com a guerra no Iraque em 2003 a constituir um elemento de tensão incontornável. A somar a outros desenvolvimentos entendidos como desfavoráveis às políticas russas, as relações a ocidente tornaram-se difíceis. O discurso de Putin na Conferência sobre Segurança de Munique em 2007 (Munich Security Conference, 2007) foi revelador do descontentamento que se desenvolveu face a decisões norte-americanas e também europeias entendidas na Rússia como contrárias aos seus interesses (por exemplo, o projeto de defesa antimíssil norte-americano ou a questão do Kosovo). Este novo período, denominado de 'neo-revisionismo' demonstra uma maior afirmação da Federação Russa no contexto internacional, ora como resultado do desenvolvimento económico e crescimento de que a Rússia beneficiou nesta década, em particular resultante da exploração de recursos energéticos, ora 
como forma de sinalizar os seus interesses e postura afirmativa no sistema internacional. ${ }^{3}$

Dmitri Medvedev mantém os alinhamentos fundamentais de Putin em matéria de política externa, combinando o crescimento que resulta do uso de recursos energéticos com um novo vetor de política externa assente no princípio de modernização, que visa várias vertentes desde investigação em áreas científicas de ponta até formação pessoal. Esta postura reflete o reconhecimento de que a política monosetorial, traduzida na dependência russa em termos económicos da exploração de recursos energéticos, e por isso também vulnerável a alterações de preços, necessita de ser revertida através do desenvolvimento de uma política de diversificação económica. Partindo do entendimento de que a política externa é condicionada por factores internos, um posicionamento doméstico sólido e de crescimento é essencial para sustentar uma política externa ativa e de reconhecimento do estatuto da Rússia no quadro internacional.

Os quatro anos da presidência de Medvedev (2008-2012) ficaram marcados pela tentativa de afirmação de políticas mais liberais não só na dimensão económica, mas também em termos de políticas sociais. Contudo, Medvedev nega publicamente essa intencionalidade e a sua caracterização como 'progressista' quando afirma que muitas vezes comentam "É um liberal. Ao que responde: Posso dizer francamente, nunca tive convicções liberais" (Barry, 2012). A sua postura política nos anos em que assumiu a presidência russa contribuiu decisivamente para o desfecho do seu primeiro mandato como colocando um ponto final na possibilidade de recandidatura. $\mathrm{O}$ anúncio antecipado da recandidatura de Vladimir Putin à presidência a 24 de setembro de 2011 demonstra claramente a necessidade sentida de reposicionamento de alinhamentos e de re-centralização de poder, face a fissuras cada vez mais evidentes no seio do Kremlin, especialmente entre as alas mais conservadoras e as alas mais liberais.

De facto, no plano externo, Medvedev conseguiu promover um desanuviamento nas relações, apesar da guerra na Geórgia já ter tido lugar sob a

\footnotetext{
3 Esta secção sobre a tipologia relativa à evolução da política externa é essencialmente informada pelo trabalho de Richard Sakwa (2012), como referenciado acima.
} 
sua presidência, mas sendo o culminar de um conjunto de desenvolvimentos entendidos na Rússia como adversos aos seus objetivos de política externa, em particular no espaço pós-soviético. O retomar de relações diplomáticas a nível multilateral e o reforço de relações bilaterais no contexto pós-Geórgia devem ser sublinhados, a par da postura de maior abertura do presidente que em grande medida contribuiu para este desanuviamento nas relações da Rússia com os seus parceiros ocidentais. Internamente, as políticas de modernização foram bem acolhidas, mas não tiveram tempo suficiente para germinar. Além do mais, permitiram maior mobilização social, o que ampliou o espaço para vozes de descontentamento e maiores reivindicações em termos de reformas políticas - um desenvolvimento que a elite no poder, especialmente centrada em Vladimir Putin, tinha que conter. O regresso de Putin à presidência russa na primavera de 2012 significa o retorno a políticas centralizadas, a contenção da voz popular, e o reforço do poder através do afastamento de elementos mais progressistas e liberais. O novo governo que se forma em resultado das legislativas de dezembro de 2011, liderado pelo anterior presidente Medvedev, visa prosseguir um curso de modernização, contudo, num ambiente pautado por linhas dirigistas e onde a autoridade centralizada é reconhecida como estrutura basilar de atuação e desenvolvimento de políticas.

As próximas secções ilustram esta evolução na política externa russa em diferentes dimensões desta, incluindo relações com a sua área de vizinhança, o ocidente (EUA e UE), e o oriente (China), demonstrando linhas de continuidade e mudança numa política que tem vindo a assumir-se, crescentemente, como assertiva num contexto internacional em mudança.

\section{A Federação Russa e a vizinhança próxima: uma assertividade crescente}

A desagregação da União Soviética implicou, como analisado, um redesenhar do espaço pós-soviético com o estabelecimento de vários novos Estados. A criação da Comunidade de Estados Independentes (CEI) em dezembro de 1991 procurou responder a um processo de desmantelamento de uma 
antiga unidade territorial, mantendo ligações fundamentais e procurando perpetuar unidade numa estrutura institucional que agregasse as novas repúblicas, à exceção dos Estados do Báltico (CIS, s.d.). A CEI, iniciativa conjunta da Rússia, Bielorrússia e Ucrânia tornou-se um instrumento central aos interesses russos na sua vizinhança próxima, entendida como referido como área privilegiada de atuação.

De facto, não é difícil perceber a relevância do espaço CEI na política externa russa. Primeiro, devido a um passado histórico partilhado e à localização geográfica desta área que lhe confere importância estratégica entre este e oeste. Segundo, dadas as ligações económicas e comerciais que uniam estes Estados no período soviético e que permanecem importantes nos dias de hoje, em particular relativamente a mercados e rotas de trânsito, com a energia a constituir um elemento central. Terceiro, devido a questões de segurança, com Moscovo a assumir um posicionamento de que instabilidade na sua área de vizinhança tem implicações diretas na sua segurança e estabilidade, bem como nesta área regional alargada (Freire, 2012b).

As relações da Federação Russa com o espaço CEI são desde o final da União Soviética matéria fundamental na agenda de Moscovo. Apesar de na fase inicial denominada de 'internacionalismo liberal' ser notória uma política de abertura e grande autonomização destes Estados face a Moscovo, as pressões domésticas face a desenvolvimentos entendidos como contrários aos interesses russos, como analisado na secção anterior, conduziram a uma alteração nas políticas para a área. Estas irão concentrar-se de forma clara no espaço CEI, assumindo mesmo um cariz de afirmação da influência que a Rússia pretende manter na área. No entanto, duas anotações são aqui importantes: primeiro, o espaço CEI não é um espaço homogéneo, e segundo, a Rússia não usufrui de poder ilimitado sobre estes Estados.

De facto, a heterogeneidade da CEI acentuou-se ao longo das últimas duas décadas, com a consolidação nestes Estados de orientações diferenciadas em termos políticos, económicos, sociais e de segurança. A evolução política face a Moscovo corresponde a opções de aproximação, distanciamento e de procura de equilíbrios, gerindo relações com outros atores na área de modo a contornar situações de grande dependência da Rússia. Exemplos concretos incluem a Arménia, país que 
mantém uma política de forte dependência de Moscovo a nível político, económico e militar; a Geórgia que reorientou a sua política a ocidente e incompatibilizou-se com Moscovo, como demonstrado na guerra do verão de 2008, analisada mais à frente; e o Azerbaijão que vai gerindo boas relações com Moscovo, mas mantendo uma postura de grande autonomia e independência, prosseguindo uma política multivetorial ancorada em opções diversificadas especialmente ao nível de relações políticas e económicas a oriente e ocidente.

Neste quadro diverso, tem sido visível a preocupação russa face a mudanças políticas nestas repúblicas procurando, por um lado, evitar desenvolvimentos contrários aos seus interesses, nomeadamente o estabelecimento de regimes de orientação pró-ocidental, como no caso da Geórgia, e a quebra de lealdades políticas e económicas fundamentais à manutenção da influência de Moscovo; e por outro, o controlo do envolvimento ativo de atores externos, em particular a UE, os EUA e a China, procurando minimizar a sua presença e influência sobre estes governos.

Relativamente ao primeiro ponto, as revoluções coloridas no espaço pós-soviético merecem especial destaque. A revolução das rosas na Geórgia (2003), a revolução laranja na Ucrânia (2004), e a revolução das túlipas no Quirguistão (2005), constituíram uma onda de mudança e contestação social e política que marcaram a política russa, espelhando o receio em Moscovo de perda de influência nestes espaços. A leitura feita dos acontecimentos sublinhava os apoios ocidentais como forma de minar a exclusividade russa neste espaço. Moscovo reiterou e caracterizou estes acontecimentos como "tentativas ocidentais de imposição de democracias em países da antiga União Soviética, com a prática de financiamento de ONGs na Rússia e em Estados vizinhos, e em usar informação como 'arma numa batalha competitiva global'" (Thorun, 2009, pp. 31-32). No entanto, os efeitos adversos destas contestações foram minimizados, à exceção do caso georgiano. De facto, o Quirguistão mantém um curso político claramente na órbita russa, tendência confirmada pela eleição de Almazbek Atambayev como presidente a 30 de outubro de 2011, e a Ucrânia assumiu um curso pró-russo após a eleição de Viktor Yanukovitch para a presidência do país em fevereiro de 2010. 
O caso da Geórgia é paradigmático do desenvolvimento de relações e do posicionamento russo no espaço CEI. A guerra na Geórgia no verão quente de 2008 corresponde a uma política de reafirmação russa na área pós-soviética. A violência nos cinco dias de confrontos armados revelou a força russa face a uma Geórgia fragilizada e sem apoios militares diretos ocidentais, em particular da Organização do Tratado do Atlântico Norte (OTAN). O não-envolvimento da Aliança Atlântica numa guerra com a Federação Russa era previsível, bem como uma rápida derrota do exército da Geórgia (muito menor em número e capacidade militar). A Federação Russa aproveitou o momento e face ao contexto mais alargado das relações russas com o ocidente, num quadro de grande instabilidade e dificuldades marcadas pelas discussões relativas ao alargamento da OTAN, ao projeto do escudo de defesa antimíssil e ao Tratado sobre Forças Convencionais na Europa, entre outros, marcou a sua posição. E fê-lo em relação ao ocidente, bem como à sua área de vizinhança, demonstrando que se necessário recorreria à força para garantir a sua posição de primazia no espaço pós-soviético. Em suma, Moscovo aproveitou a oportunidade para demarcar linhas de influência e interferência, enfraquecendo a Geórgia, sinalizando a sua política afirmativa no espaço CEI, reforçando a sua estratégia de contenção dos Estados Unidos na Eurásia, e sublinhando o reconhecimento de estatuto que tem prosseguido no sistema internacional.

Como analisado, a CEI assume desde cedo relevância no discurso da Federação Russa. Logo com Ieltsin, no documento de política externa de 1993 (Foreign Policy Concept, 1993) as referências ao "estrangeiro próximo" são evidenciadas. Na altura a área era mencionada como parte dos "interesses vitais" da Rússia, constituindo uma "prioridade máxima" e sendo de "importância fundamental". O reforço deste posicionamento é claro em 2000, quando a CEI é definida como "área prioritária” onde é dada primazia ao "desenvolvimento de boas relações de vizinhança e parceria(s) estratégica(s)" (Russian Foreign Policy Document, 2000) com os Estados CEI ('parceiros tradicionais' da Rússia. Num Estudo sobre Política Externa da Federação Russa conduzido pelo Ministério dos Negócios Estrangeiros (Survey of Russian Federation Foreign Policy, 2007) a CEI é referida como prioridade essencialmente devido a factores económicos e de segurança. 
O documento indica que a Rússia pretende vizinhos na sua periferia que sejam amigáveis, prossigam políticas de desenvolvimento, uma orientação democrática e premeiem a estabilidade. O Conceito de Política Externa de 2008 (Foreign Policy Concept, 2008) reitera o significado do espaço CEI, sublinha a relevância da cooperação dentro da CEI e especialmente no quadro da Organização do Tratado de Segurança Coletiva, definido como "um instrumento fundamental para a manutenção de estabilidade e segurança na área da CEI" que se deve tornar "uma instituição central para garantir segurança na sua área de responsabilidade”, em diversos âmbitos, desde a atividade comercial e a proteção de minorias, até à luta contra o terrorismo (ver também Medvedev, 2008b). O documento inclui ainda uma referência interessante às "parcerias e alianças estratégicas [que] são desenvolvidas com os Estados que demonstrarem vontade em fazê-1o" (Foreign Policy Concept, 2008), evidenciando o reconhecimento da crescente diversidade que a CEI representa.

As políticas de Putin e Medvedev para a CEI têm sido desenvolvidas numa linha de reafirmação da influência russa na área e do prosseguimento de reconhecimento do seu estatuto a nível internacional como grande potência. A diversidade existente neste espaço, em particular ao nível das riquezas energéticas e da capacidade de independência política face à Rússia, constitui um desafio e tem exigido políticas de reajustamento e de atração da parte da Federação Russa. É de realçar, que num quadro nem sempre favorável, como analisado, a Rússia tem recuperado influência e poder na sua vizinhança próxima, através da combinação de políticas mais interventivas a nível militar e económico, bem como da promoção de programas de cariz educativo ou cultural, que têm também desempenhado um importante papel na aproximação a alguns destes Estados (com especial relevância nesta dimensão para as relações da Rússia com as repúblicas da Ásia Central (Freire, 2009). A formulação dos sucessivos conceitos de política externa e a forma como estes consagram a CEI como área prioritária tem servido como guia de ação da Rússia para este espaço, não significando no entanto a definição de uma estratégia clara para a área. Esta indefinição é visível em políticas reativas, muitas vezes decorrentes da presença de atores 
externos e/ou do aumento de influência e autonomia dos países nesta área de importância vital.

O acordo relativo a uma área de comércio livre alcançado dia 19 de outubro de 2011, na Cimeira da CEI entre a Rússia, Ucrânia, Bielorrússia, Cazaquistão, Arménia, Quirguistão, Moldova, e Tajiquistão, visa facilitar as trocas comerciais reduzindo tarifas para um número alargado de produtos. Do acordo, que entrou em vigor em janeiro de 2012, apenas ficaram fora o Azerbaijão, o Uzbequistão e o Turquemenistão. Esta proposta liderada pela Rússia, a par do anúncio do primeiro ministro Putin em finais de 2011 do objetivo de estabelecimento de uma União Euroasiática, com integração política e económica na linha da experiência da União Europeia, demonstra a vontade da Rússia de incutir novo dinamismo no contexto da CEI. Em fevereiro de 2012, a criação da Comissão Económica Euroasiática constituiu um passo importante na consolidação deste projeto, que é esperado possa ser concretizado numa união económica em 2015.

A Rússia tem prosseguido uma política de renovação do quadro CEI enquanto fórum multilateral, e a concretização da área de comércio livre, a par da projeção da possibilidade de avançar para uma união económica, reforça a presença russa e o objetivo de integração desta área. Os desenvolvimentos no espaço CEI não têm sido completamente favoráveis às políticas russas, como o caso da Geórgia bem ilustra e que culminou na sua retirada da Comunidade, contudo, e apesar de não ter poder ilimitado na área, a Rússia tem procurado reforçar laços, não só através de iniciativas de cariz económico, como também do reforço de proximidade cultural, e em alguns casos, de maior cooperação no âmbito militar. Os exercícios miliares no âmbito da Organização do Tratado de Segurança Coletiva na Arménia em setembro de 2012 são reveladores do posicionamento que a Rússia pretende que lhe seja reconhecido, sublinhando que não será mera observadora da instabilidade que vem aumentando nas relações entre a Arménia e o Azerbaijão. Estas ações revelam uma estratégia que Moscovo tem promovido no sentido de agilizar a sua capacidade de ação no espaço pós-soviético, aumentando a sua margem de manobra face a políticas mais autónomas e independentes de muitos destes Estados, e minimizando o envolvimento e atuação de atores externos, como analisado em seguida. 


\section{As relações com os EUA e a UE no contexto da transição russa}

As relações da Federação Russa com o ocidente percorreram um caminho sinuoso desde o final da União Soviética aos nossos dias. O período do 'internacionalismo liberal' que marcou o início dos anos 1990 foi caracterizado por uma aproximação e abertura a ocidente, com a inclusão da Federação Russa em vários fóruns institucionais que se mantém ainda, embora com contornos diferenciados. Esta fase nas relações a ocidente é marcada pelo discurso da 'casa comum europeia' e da desconstrução da rivalidade bipolar que marcou toda a Guerra Fria. Numa lógica de desanuviamento, permitiu que o reajustamento internacional ao novo ordenamento se fizesse com base num espírito cooperativo. Contudo, condicionantes internas na Rússia, nomeadamente a pressão de grupos mais nacionalistas e comunistas, e externas, incluindo uma resposta ocidental de apoio aquém das expetativas, além de um alargamento da influência ocidental no espaço pós-soviético, conduziram a uma nova fase nas relações - a 'competitividade pragmática'.

A Federação Russa assume um posicionamento mais autónomo face ao ocidente e mais assertivo face ao espaço CEI, como analisado. A chegada de Evgeny Primakov ao Ministério dos Negócios Estrangeiros, o diplomata conhecido como o Eurasianista, traz novas linhas de orientação à política externa, onde um maior equilíbrio deve ser dado às relações a ocidente e a oriente. Ou seja, a política externa russa deve assumir-se como multivetorial, e deve gerir os benefícios que os equilíbrios resultantes desta postura permitem. Assim tem sido desde então, embora a gestão de princípios e pressupostos diferenciados implique dificuldades no ajustamento de políticas.

As relações com a União Europeia consolidaram-se com a assinatura do Acordo de Parceria e Cooperação (APC) em dezembro de 1997, por um período de dez anos, e que estabelecia as bases legais da relação. Amplo nos princípios que engloba, desde relações políticas, culturais, económicas e comerciais, assume como pressupostos de base o diálogo, a partilha de valores e princípios de cooperação. No entanto, é importante sublinhar que a Federação Russa e a UE são dois atores desiguais, em 
vários aspetos, mas especialmente nesta parceria pelo facto da primeira ser um Estado e a segunda uma organização internacional. Este aspeto é importante ao nível da negociação e implementação de acordos, que se tem revelado por vezes morosa e muitas vezes ineficaz.

Além do mais, a partilha de princípios e a base de diálogo firmadas têm enfrentado entendimentos diferenciados de 'democracia', 'respeito por direitos humanos', 'estado de direito', entre outros. As linhas definidoras da relação são, pela diversidade de entendimentos e pela diferenciação entre os atores, mais linhas orientadoras do que a base de uma parceria consolidada entre ambos. Revelador destas dificuldades é a não renovação do APC volvidos mais de dez anos após a sua assinatura, e num quadro internacional mudado. Apesar da sua renovação anual automática, como previsto na letra do texto, é muito relevante a incapacidade em renegociar um novo texto refundador da relação legal. Desde 2007 assim tem sido, e as conversações têm-se arrastado, sendo que a admissão da Rússia na Organização Mundial do Comércio, um desejo de longa data concretizado em dezembro de 2011, poderá significar novos avanços nesta matéria, oferecendo possibilidades de cooperação diferenciadas (De Gucht, 2012).

Em 2005 foi assinado o Acordo sobre os Quatro Espaços Comuns em São Petersburgo, consolidado em 2005 com a aprovação do roadmap para a sua implementação. E este tem sido o documento de referência no desenvolvimento das relações bilaterais, mantendo o carácter abrangente em termos de áreas de atuação (Espaço económico comum; Espaço comum de liberdade, segurança e justiça; Espaço comum de cooperação no âmbito da segurança externa; e Espaço comum de investigação, educação e cultura), e segue os pressupostos de diálogo e cooperação do acordo inicial. A parceria estratégica definida inclui como linha fundamental a estabilização e desenvolvimento da área de vizinhança partilhada. Esta é objeto de leituras diferentes na Rússia e na UE. Como analisado, para a Rússia assume uma importância vital sendo considerada área primária de atuação da sua política externa; para a UE representa um vasto mercado e grande potencialidade em particular em matéria energética. 
O desenvolvimento da Política Europeia de Vizinhança (PEV) ${ }^{4}$ resultado do alargamento da União de 2004, com enfoque mais especializado no espaço pós-soviético através da Parceria a Leste criada em maio de 2009 (que inclui os três países do Cáucaso do Sul, a Bielorrússia, a Moldova e a Ucrânia), é entendido por Moscovo como ingerência no seu espaço preferencial de atuação e tem gerado algum descontentamento, com implicações na relação bilateral. As acusações de Moscovo relativas ao apoio da UE às revoluções coloridas, constituem disso um exemplo. Demonstram ainda como o conceito de "vizinhança partilhada" é um conceito que sugere divergências e com o qual a Rússia se sente desconfortável face a um espaço que entende como de influência vital para os seus interesses e objetivos de política externa.

É interessante notar que apesar das relações Rússia-UE serem genericamente mais estáveis do que as relações Rússia-EUA, as primeiras refletem muitas vezes os desentendimentos nas segundas. A tensão nas relações em 2007 e 2008 resultante das políticas de alargamento da Aliança Atlântica, do projeto dos EUA de escudo de defesa anti-míssil, e do que era entendido em Moscovo como ingerência alargada no espaço pós-soviético, entre outros, implicaram diretamente a UE. E, claramente, um dos momentos mais difíceis na relação bilateral prendeu-se com a Guerra na Geórgia em agosto de 2008. Pouco antes, em junho de 2008 na Cimeira UE-Rússia de Kanti-Mansiisk haviam sido finalmente lançadas oficialmente as negociações para um novo acordo APC, que são imediatamente suspensas face aos acontecimentos na Geórgia. No entanto, cedo é retomado o diálogo após a mediação da UE, e em novembro na Cimeira de Nice é confirmado o retorno às negociações para um novo acordo, ainda não alcançado. Uma demonstração de que ambos reconhecem a relevância da parceria e do diálogo num contexto de grande interdependência. No entanto, o novo quadro 'neo-revisionista' russo traça um novo mapeamento para estas relações, exigindo maior paridade no âmbito da denominada parceria estratégica.

\footnotetext{
${ }^{4}$ Os países PEV incluem na sua dimensão sul a Argélia, Egito, Israel, Jordânia, Líbano, Líbia, Autoridade Palestiniana, Síria, e Tunísia; e na dimensão leste a Arménia, Azerbaijão, Bielorrússia, Geórgia, Moldova, Marrocos, e Ucrânia.
} 
O regresso de Vladimir Putin à presidência tem aqui implicações claras pelas medidas centralizadoras e mais restritivas em termos de atuação nas políticas interna e externa. O retrocesso nos princípios de mobilização social, de limitação de diálogo, de intolerância face a visões distintas, visível por exemplo no cerco à oposição e no encerramento de missões políticas estrangeiras na Rússia, veio marcar o novo cenário político no país. Catherine Ashton, a Alta Representante da UE para os Negócios Estrangeiros e a Política de Segurança deixou já clara a preocupação em Bruxelas por estes desenvolvimentos que claramente implicam um passo atrás nas políticas de abertura de Medvedev e que fazem regressar às agendas políticas discursos críticos e de preocupação face a uma Rússia assumidamente revisionista (Ashton, 2012a e 2012b).

No que concerne as relações com os EUA estas seguem maior sinuosidade. Do apoio imediato e solidariedade russa na altura dos ataques terroristas de 11 de setembro de 2001 nos Estados Unidos até às acusações de criação de linhas divisórias e de procura de hegemonia perniciosa no sistema internacional, na Conferência sobre Segurança de Munique em 2007 (Munich Security Conference, 2007), as relações bilaterais têm sido objeto de cooperação e rivalidade, sublinhando o 'novo realismo' que caracterizou a presidência de Vladimir Putin, e o período de 'neo-revisionismo' que se inicia nesta altura com uma postura mais assertiva da Rússia.

Os temas de desacordo entre os Estados Unidos e a Rússia, nesta leitura alargada de uma relação com contornos múltiplos, são vários e têm implicações muito concretas ao nível do diálogo e em termos de implementação de políticas. Sem pretender elaborar uma lista exaustiva, são de realçar: (i) a questão sempre difícil do alargamento da OTAN com uma aproximação às fronteiras russas (com o recuo norte-americano no seu apoio à aprovação dos Planos de Adesão da Ucrânia e Geórgia, na Cimeira de Bucareste da Aliança Atlântica, na primavera de 2008, entendido na Rússia como uma vitória diplomática); (ii) a retirada unilateral dos Estados Unidos do Tratado sobre Mísseis Anti-Balísticos (Tratado ABM), em 2001, apesar da assinatura de um novo Tratado em maio de 2002 relativo à redução de armas nucleares de longo alcance - o Tratado de Redução [de Armas] Ofensivas Estratégicas, mas de alcance bastante mais limitado; (iii) o 
projeto do presidente George W. Bush de desenvolvimento de um escudo de defesa antimíssil e de instalação de equipamentos relacionados com este em território europeu, nomeadamente na Polónia e República Checa; (iv) a postura norte-americana no Iraque, que levou a críticas duras da parte da Rússia; (v) o reconhecimento da independência do Kosovo fora do quadro do Conselho de Segurança das Nações Unidas; (vi) o envolvimento alargado no espaço pós-soviético, nomeadamente através de uma presença militar na Ásia Central consentida pela Rússia, mas que se prolongava no tempo, e o que foi considerado como apoio direto às revoluções coloridas na Geórgia, Ucrânia e mais tarde Quirguistão, fomentando políticas anti-russas nestas repúblicas; e (vii) o posicionamento diferenciado face à questão da violência prolongada na Síria. Estes são aspetos concretos da agenda de dissensão que contribuíram para uma deterioração gradual, mas clara, das relações entre os Estados Unidos e a Rússia.

A retirada unilateral russa do Tratado sobre Forças Convencionais na Europa (Tratado CFE), a não-renovação do Acordo de Parceria e Cooperação com a UE, o aprofundamento da cooperação no âmbito da Organização de Cooperação de Xangai, com especial relevância para a China (analisada na próxima secção), incluindo a realização de vários exercícios militares, e o discurso duro proferido por Putin em Munique em 2007, são demonstrativos do nível de tensão a que as relações foram votadas. Em Munique, o presidente russo afirmava que os Estados Unidos "ultrapassaram as suas fronteiras nacionais por todos os meios. Isto é visível nas políticas económicas, culturais e educativas que impõe a outras nações”, e adicionava ainda que a Rússia é um Estado diferente, disposto a interagir com "parceiros responsáveis e independentes com quem possa trabalhar conjuntamente na construção de uma ordem mundial justa e democrática que seja capaz de assegurar segurança e prosperidade não apenas de alguns selecionados, mas de todos". Neste período surgem mesmo um conjunto de publicações que cunham de 'uma nova Guerra Fria' a dificuldade de relacionamento bilateral, o que refletiu um exagero terminológico dado o carácter de interdependência e as bases de diálogo existentes entre as partes, mesmo no período mais difícil aquando dos confrontos armados na Geórgia. 
O pós-Geórgia constitui o momento de reajustamento concretizado na reset policy promovida pela administração norte-americana de Barack Obama, e que tomou forma a partir da primavera de 2009, numa declaração conjunta dos presidentes norte-americano e russo em Londres. Esta afirmava que estamos "prontos para avançar para além das mentalidades da Guerra Fria e esboçar um novo recomeço nas relações entre os dois países" (Joint Statement, 2009), princípio reforçado aquando da visita de Obama a Moscovo em julho de 2009, tendo em vista um discurso e uma prática mais moderada que anteriormente. A criação da Comissão Presidencial Bilateral Estados Unidos-Rússia, ${ }^{5}$ com 16 áreas de intervenção desde contra terrorismo e controlo de armamento até agricultura e cooperação espacial, sinaliza a nova postura.

Nesta linha de promoção de confiança, Sergei Ryabkov afirma que apesar dos temas de divergência não desaparecerem de forma mágica, há condições para "formar visões estratégicas comuns e abordagens táticas em várias áreas (...), contudo, encontrar soluções consensuais exige trabalho árduo bem como forte compromisso. Só é possível se confiarmos mutuamente e se todos cumprirmos as nossas obrigações" (Ryabkov, 2010, p. 208).

O objetivo é a construção de diálogo efetivo e o desenvolvimento de cooperação em áreas consideradas fundamentais, como no quadro da redução ou limitação de armamentos, não proliferação, e estabilização de áreas de interesse estratégico, nomeadamente o Afeganistão. Neste quadro, a ratificação do Tratado START, sobre redução de armas estratégicas, em janeiro de 2011 é exemplar. Em conjunto, Estados Unidos e Rússia detêm cerca de $90 \%$ do arsenal nuclear a nível mundial, pelo que a ratificação de um acordo que visa redução de arsenais, inspeções conjuntas e troca de informações numa lógica de transparência e consolidação de confiança, é um passo assumidamente positivo na consolidação da parceria estratégica.

Neste quadro de aproximação, a administração Obama redefiniu o projeto de defesa antimíssil propondo uma alternativa faseada e com envolvimento (ainda a clarificar) russo, ou seja, com contornos bem

\footnotetext{
5 Mais informação disponível em http://www.state.gov/p/eur/ci/rs/usrussiabilat/index.htm.
} 
diferenciados da proposta original. Contudo, persistem dificuldades e "é preciso novo software" na base deste relacionamento (Antonenko, 2009, p. 228), que terá que passar pela definição de uma linguagem comum e de ação também ela partilhada.

A questão síria que tem ensombrado o relacionamento bilateral merece ainda destaque. A campanha presidencial nos EUA, durante o ano de 2012 afiou, como usual, a retórica e o discurso político cada vez mais crítico de uma Rússia distante que não se rege pelos mesmos princípios ordenadores. Mas para além da retórica política, parece claro no seio das elites governativas nos Estados Unidos que o regresso de Vladimir Putin pôs termo a três anos em que claramente foram registados avanços no relacionamento bilateral. O caso da Síria e a postura de força russa no seu apoio à autoridade instituída tem contribuído claramente para o aumento de fricção, a par de outras medidas provocadoras, como por exemplo o encerramento das representações da USAID no país, resultante de uma nova lei publicada em julho de 2012 e que exige o registo de todas as organizações não governamentais financiadas externamente como agentes estrangeiros, à qual várias ONGs reagiram negativamente. Além do mais, as autoridades russas acusam a USAID de imiscuição em questões políticas sensíveis à segurança nacional, como o seu envolvimento com rebeldes islâmicos no Cáucaso do Norte, e de por isso mesmo, esta decisão de encerramento resultar do entendimento russo de que a ONG está a agir para lá dos contornos do seu mandato (RFE/RL, 2012). Dificuldades acrescidas e que no novo registo político de Putin na presidência parecem sublinhar o regresso de um clima gélido às relações bilaterais.

A participação russa na Cimeira da OTAN em novembro de $2010 \mathrm{em}$ Lisboa marcou de forma vincada a melhoria nas relações bilaterais, pela representação ao mais alto nível da Rússia na cimeira, na pessoa do presidente, e pelas conversações relativas aos princípios definidores da possível cooperação russa no projeto antimíssil, revelando uma abertura cuja sinalização foi muito positiva. Apesar de áreas de desentendimento, momentos de tensão, expetativas frustradas, a possibilidade de cooperação na diferença constituiu um novo registo na redefinição desta relação bilateral, que deve ser relembrado. O 'espírito de Lisboa' como foi cunhado informalmente por 
diplomatas russos sinalizava este mesmo entendimento, o de que a diferença não tem que ser um obstáculo inviabilizador de maior cooperação. Contudo, após este período de maior abertura, as relações entre ambos voltaram em inícios de 2012 a contrair, e medidas numa linha de dureza política, como o caso da expulsão da representação da USAID, apenas vêm adensar sombras que se vão formando em torno do relacionamento bilateral e que parecem apontar para a criação de dificuldades adicionais nos vários setores de cooperação bilateral, bem como no âmbito de quadros multilaterais onde se refletem este tipo de problemas, nomeadamente a Aliança Atlântica.

\section{Relações com a China: entre contenção e cooperação}

As relações da Federação Russa com a República Popular da China seguiram um curso diferenciado das relações com o ocidente. A 'competitividade pragmática' alternando cooperação e competição tem sido a linha marcante neste relacionamento bilateral. De qualquer modo, é importante notar que a leitura das relações Rússia-China não se deve fazer sem o enquadramento mais lato das relações da Rússia num quadro multivetorial. Aliás, algumas dinâmicas no quadro da Organização de Cooperação de Xangai são reflexo de procura de equilíbrios não só em relação à própria China, mas também em relação a outros atores, em particular os EUA. Contudo, deve ser notado que a evolução deste relacionamento bilateral ao longo dos últimos anos tem sido prosseguida em contraciclo face às relações a ocidente onde tem sido visível maior tensão. O regresso de Vladimir Putin à presidência russa, em maio de 2012 enquanto sugerindo dificuldades acrescidas no relacionamento com os EUA, como analisado, parece possibilitar o estreitar de cooperação com a China.

A base de pragmatismo nesta relação não esconde as diferenças existentes nos entendimentos de identidade no sistema internacional e de integração em projetos multilaterais. ${ }^{6}$ Por exemplo, a procura de

\footnotetext{
${ }^{6}$ O desenvolvimento de conteúdos desta secção é informado por trabalho desenvolvido anteriormente. Ver Freire e Mendes (2009).
} 
apoio da Rússia para o reconhecimento das independências da Abcázia e Ossétia do Sul no rescaldo da guerra na Geórgia em 2008, não encontrou sustentação. Na Cimeira de Dushanbe em agosto de 2008 a Rússia foi mesmo criticada pelos seus parceiros pelo facto de ter violado um pressuposto fundamental da organização, entendido como o não apoio a movimentos separatistas, abrindo um precedente que poderia ter consequências imprevistas em vários Estados desta região alargada. A Declaração Final acabou por conter apenas uma referência de preocupação face aos acontecimentos e de que "as partes relevantes devem resolver os problemas existentes de forma pacífica e através de diálogo, desenvolver esforços de reconciliação e facilitar negociações (Declaração de Dushanbe, 2008). Este exemplo ilustra a inexistência de solidariedade entre os membros em termos de princípios, bem como o facto de a Rússia não assumir um papel de primazia no seio da mesma, face à China. Como afirma Stephen Blank (2008), a parceria sino-russa não corresponde de forma alguma a uma aliança.

As relações entre a China e a Rússia foram reforçadas com a assinatura em julho de 2001 do Tratado de Boa Vizinhança e Cooperação Amigável (Treaty of Good-Neighborliness, 2001), que consolida a ideia de parceria estratégica, embora no seu conteúdo se revele um documento regulador, especialmente em matéria de venda de armamento, e questões energéticas com uma Rússia produtora e uma China consumidora. Assim, o documento revela-se limitado em termos da definição e operacionalização de uma relação estratégica entre estes dois atores. Os acontecimentos pós-11 de setembro e a postura dos EUA de maior assertividade contribuíram, no entanto, para uma aproximação entre a Rússia e a China, num quadro internacional entendido como desfavorável. A defesa da multipolaridade tem estado presente nos discursos russos e chineses (China Elections and Governance, 2007 e Putin, 2006), e o entendimento das políticas norte-americanas como afirmação de hegemonia choca diretamente com os interesses chineses e russos. Assim, esta tem sido essencialmente uma parceria estratégica construída pela negativa, ou seja, por oposição a uma posição de afirmação dos EUA (Freire e Mendes, 2009). Mesmo em termos de conteúdo a relação tem incidido essencialmente em temas económicos. 
A nível bilateral e com contornos regionais, a preocupação com minorias e separatismo, com os casos da Chechénia na Rússia e Xinjiang na China, por exemplo, e o aumento do radicalismo islâmico têm oferecido espaço de cooperação. O discurso do princípio da inviolabilidade da integridade territorial do Estado é, sem surpresa, partilhado. A par deste, a não ingerência em assuntos internos com particular enfoque em questões de direitos humanos e liberdades fundamentais é também sublinhada. A cooperação no combate ao terrorismo e criminalidade organizada faz também parte da agenda. Em termos militares, a realização de vários exercícios conjuntos de natureza bilateral e no contexto da Organização de Cooperação de Xangai reforça a dimensão securitária desta relação. Por exemplo, a Peace Mission 2005 foi o primeiro exercício bilateral conjunto envolvendo forças aéreas, terrestres e marítimas. No quadro da Organização de Cooperação de Xangai, o primeiro exercício militar teve lugar em 2003, e vários outros lhe têm sucedido. O não direcionamento destas ações contra qualquer país terceiro tem sido reforçado, sendo estas ações justificadas com base no aumento da segurança da vasta área da Ásia Pacífico, e deste modo numa lógica de cooperação intra-organizacional e não de contenção de terceiros.

Apesar da forte dimensão económica implícita nesta relação não há uma integração económica densa entre a China e a Rússia. Os índices de integração comercial, por exemplo, são baixos, de acordo com dados estatísticos oficiais de ambos os países. ${ }^{7}$ Em termos de comércio de armamento tem havido uma política de retraimento de Moscovo acautelando o poder emergente da China e uma eventual paridade a este nível.

7 Ver, por exemplo, Federal State Statistics Service, Russian Federation: "Foreign Trade of the Russian Federation with Far Abroad Countries", http://www.gks.ru/free_doc/2007/ b07_12/25-05.htm; "Distribution of Export and Import of the Russian Federation by some Foreign Countries",

http://www.gks.ru/free_doc/2006/rus06e/25-07.htm. Ministry of Commerce of the People's Republic of China: "Imports and Exports between China and European Countries (2007/1-5)", Table 1, Department of European Affairs, 12 June 2007,

http://english.mofcom.gov.cn/aarticle/statistic/chinaeuropeancountry/200707/20070704880231. html; "Imports and Exports between China and European Countries (2007/1-5)", Table 2,

Department of European Affairs, 12 June 2007,

http://english.mofcom.gov.cn/aarticle/statistic/chinaeuropeancountry/200707/20070704880390. html. Ver ainda Freire e Mendes, 2009. 
Questões de migração e problemas fronteiriços têm estado na agenda, e apesar dos acordos que têm sido negociados estes foram problemas que colocaram pressão na relação.

Assim, a relação sino-russa apresenta contornos pragmáticos de dupla contenção (entre os dois principais parceiros no quadro da Organização de Xangai, Rússia e China) e para com os EUA. Mas esta contenção não significa hostilidade para com os Estados Unidos. Da análise fica claro que as relações entre a Rússia e os EUA flutuam entre tensão e cooperação e o mesmo se passa em relação à China. A importância geopolítica dos EUA é reconhecida, bem como a relevância da manutenção de diálogo. As linhas de pragmatismo que têm sublinhado esta relação parecem manter-se, incorporando elementos de maior cooperação e factores de alguma tensão, mas numa lógica onde um espírito cooperativo tem prevalecido. E este tem-se traduzido em alguns avanços que merecem destaque, nomeadamente a resolução dos problemas fronteiriços, que constituía uma questão de grande delicadeza diplomática, e o redesenho dos contornos da relação na denominada parceria estratégica coordenada alargada, que visa o reconhecimento de posições conjuntas próximas face a grandes temas da atualidade internacional. Além do mais, a definição de objetivos de crescimento económico conjuntos, onde o aumento do comércio bilateral já se faz notar, a par de iniciativas culturais que procuram aproximar comunidades, demonstram os objetivos de coordenação que as lideranças russa e chinesa têm desenvolvido. Seja numa lógica positiva de cooperação ou numa lógica negativa de competição face a atores externos, ou ambas, está em curso a consolidação de relações de proximidade, que Putin pretende adensar (Xinhuanet, 2012).

\section{Conclusão}

A evolução da política externa russa desde o final da União Soviética aos nossos dias tem-se revelado um processo complexo com diversas variáveis. A inter-relação entre a transição a nível doméstico, como analisado, e a transição no sistema internacional, é evidente e marca o 
percurso seguido pela Federação Russa nos últimos vinte anos. De uma postura de 'internacionalismo liberal' muito apoiada na aproximação ao ocidente, a política russa evoluiu para uma posição de 'competitividade pragmática' onde a multivetorialidade da sua política externa se assume com preponderância. Na prossecução dos seus objetivos de reafirmação no contexto internacional e de procura de reconhecimento de estatuto pelos seus pares como grande potência - num quadro lido como multipolar - a Rússia adota o 'novo realismo' com um discurso mais inflamado face ao que entende como políticas e práticas promovidas especialmente pelos parceiros ocidentais, como contrários aos seus interesses. Como ilustrado no texto, o 'neo-revisionismo' que resulta do quadro de tensão que culmina na guerra da Geórgia em 2008, mantém-se como alinhamento fundamental nos dias de hoje, e ao longo da presidência de Medvedev. Uma política que deverá ser mantida e prosseguida pela Rússia de Vladimir Putin nos próximos anos.

\section{Bibliografia}

ANTONENKO, Oksana - Mr. Obama goes to Moscow. Survival. Vol. 51, N. 5 (2009), p. 227-231.

ASHTON, Catherine (2012a) "Statement by EU High Representative Catherine Ashton in the European Parliament on the political use of justice in Russia", Strasbourg, 11 setembro, A 403/12. [Acedido a 14 de set. de 2012]. Disponível na Internet: http://www.consilium.europa.eu/uedocs/cms_Data/docs/pressdata/EN/foraff/132370. pdf.

ASHTON, Catherine (2012b) "Statement by High Representative Catherine Ashton on the wave of violent attacks against diplomatic missions", Brussels, 14 setembro, A 410/12. [Acedido a 14 de set. de 2012]. Disponível na Internet: http://www.consilium.europa. eu/uedocs/cms_Data/docs/pressdata/EN/foraff/132457.pdf.

BARRY, Ellen - Leaving the Presidency in Russia, Medvedev Fights for Relevance. The New York Times, 3 maio 2012. [Acedido a 4 de jun. de 2012]. Disponível na Internet: http:// www.nytimes.com/2012/05/04/world/europe/leaving-presidency-russias-medvedevfights-for-relevance.html?_r=0.

BLANK, Stephen - The Shanghai Cooperation Organization and the Georgian Crisis. China Brief. Vol. 8, N. ${ }^{\circ} 17$ (2008). [Acedido a 9 de jan. de 2012]. Disponível na Internet: http://www.jamestown.org/single/?no_cache=1\&tx_ttnews\%5Btt_news\%5D=5134.

China Elections and Governance - China, Russia sign joint communiqué, pledging to broaden strategic co-op. China Elections and Governance, 7 novembro 2007. [Acedido a 9 de jan. de 2012]. Disponível na Internet: http://en.chinaelections.org/newsinfo. asp? newsid=12598. 
CIS (s.d.) Commonwealth of Independent States official webpage. [Acedido a 9 de jan. de 2012]. Disponível na Internet: http://www.cisstat.com/eng/cis.htm.

Constitution of the Russian Federation (1993) The Constitution of the Russian Federation, Adopted at the December 12, 1993 referendum. [Acedido a 9 de jun. de 2012]. Disponível na Internet: http://www.mid.ru/ns-osndoc.nsf/1e5f0de28fe 77 fdcc32575d900298676/ d0bd6a5ba542c949c32575dd004009ee?OpenDocument.

DE GUCHT, Karel - Karel De Gucht European Commissioner for Trade Seizing the Opportunity: EU-Russia Relations beyond the WTO Seminar on EU-Russia Trade and Economic Relations, Helsinki, Finland 7 September 2012. SPEECH/12/590, 7 setembro. [Acedido a 14 de set. de 2012]. Disponível na Internet: http://europa.eu/rapid/pressReleasesAction. do? reference $=$ SPEECH/12/590\& format $=$ HTML\&aged $=0 \&$ language $=E N \&$ guiLanguage $=e n$.

Declaração de Dushanbe - Dushanbe Declaration of Heads of SCO Member States. Agosto 2008. [Acedido a 9 de jan. de 2012]. Disponível na Internet: http://en.sco2009.ru/ docs/documents/index.html.

Foreign Policy Concept (1993) Russian Federation. Janeiro.

Foreign Policy Concept (2000) Russian Federation. Approved by the President of the Russian Federation V. Putin, 28 junho. [Acedido a 2 de mar. de 2011]. Disponível na Internet: http://www.fas.org/nuke/guide/russia/doctrine/econcept.htm.

Foreign Policy Concept (2008) Russian Federation. Approved by Dmitry A. Medvedev, President of the Russian Federation, 12 julho. [Acedido a 30 de mar. de 2011]. Disponível na Internet: http://www.mid.ru/ns-osndoc.nsf/1e5f0de28fe 77 fdcc32575d900298676/8 69c9d2b87ad8014c32575d9002b1c38?OpenDocument.

Foreign Policy Concept (2013) Russian Federation. Approved by President of the Russian Federation V. Putin, 12 fevereiro. [Acedido a 10 de jan. de 2013]. Disponível na Internet: http://www.mid.ru/brp_4.nsf/0/76389FEC168189ED44257B2E0039B16D.

FREIRE, Maria Raquel - Russia's Energy Policies in Eurasia: Empowerment or Entrapment?. In Kanet, Roger E. e Freire, Maria Raquel (org.), Russia and Its Near Neighbours: Identity, Interests and Foreign Policy. Basingstoke: Palgrave Macmillan, 2012.

FREIRE, Maria Raquel - Russian Foreign Policy towards its Neighbourhood: A Complex Mosaic of Relations. In Kanet, Roger E. e Freire, Maria Raquel (org.), Competing for Influence: The EU and Russia in Post-Soviet Eurasia. Dordrecht: Republic of Letters Publishing, 2012.

FREIRE, Maria Raquel - USSR/Russian Federation Major Power Status Inconsistencies. In Volgy, Thomas; Corbetta, Renato; Grant, Keith e Baird, Ryan (org.), Major Powers and the Quest for Status in International Politics: Global and Regional Perspectives. Basingstoke: Palgrave Macmillan, 2011.

FREIRE, Maria Raquel - Russian Politics toward Central Asia: Supporting, Balancing, Coercing or Imposing?. Asian Perspective. Vol. 33, N. ${ }^{\circ} 2$ (2009), p. 125-149.

FREIRE, Maria Raquel e MENDES, Carmen Amado - Realpolitik Dynamics and Image Construction in the Russia-China Relationship: Forging a Strategic Partnership?. Journal of Current Chinese Affairs. N. ${ }^{\circ} 2$ (2009), p. 27-52.

Joint Statement - Joint Statement by President Barack Obama and President Dmitry A. Medvedev of Russia. Administration of Barack H. Obama, Compilation of Presidential Documents, 1 abril 2009, DCPD Nr: DCPD200900208. [Acedido a 9 de jan. de 2012]. Disponível na Internet: http://www.gpo.gov/fdsys/pkg/DCPD-200900208/pdf/DCPD-200900208.pdf.

MEDVEDEV, Dmitry - Speech at the Meeting with Russian Ambassadors and Permanent Representatives to International Organisations. Statements on Major Issues, Russian Foreign Ministry, Moscovo, 15 julho 2008. [Acedido a 2 de mar. de 2011]. Disponível na Internet: : http://www.norway.mid.ru/old/news_fp/news_fp_81_eng.html. 
Munich Security Conference - Discurso do presidente da Federação Russa Vladimir Putin, 10 fevereiro 2007. [Acedido a 9 de jan. de 2012]. Disponível na Internet: http://www. securityconference.de/Putin-s-speech.381+M52087573ab0.0.html.

PUTIN, Vladimir - Written Interview given by President Vladimir Putin to Chinese News Agency Xinhua. Russian Presidency, 20 março 2006. [Acedido a 9 de jan. de 2012]. Disponível na Internet: http://www.kremlin.ru/eng/text/speeches/2006/03/20/1117_ type82916_103264.shtml.

RFE/RL - Russia Shut Downs USAID Activities. 19 setembro 2012. [Acedido a 19 de set. de 2012]. Disponível na Internet: http://www.rferl.org/content/moscow-shuts-downusaid-activities-in-russia/24712579.html.

RYABKOV, Sergei - An Interview with Sergey Ryabkov. Journal of International Affairs. Vol. 63, N. ${ }^{\circ} 2$ (2010), p. 207-216.

Survey of Russian Federation Foreign Policy - Ministry of Foreign Affairs of the Russian Federation, Department of Information and Press, 2007. [Acedido a 11 de mar. de 2011]. Disponível na Internet: http://www.mid.ru/brp_4.nsf/e78a48070f128a7b43256 999005bcbb3/89a30b3a6b65b4f2c32572d700292f74? OpenDocument.

THORUN, Christian - Explaining Change in Russian Foreign Policy: The Role of Ideas in Post-Soviet Russia's Conduct Towards the West. Basingstoke: Palgrave Macmillan, 2009.

Treaty of Good-Neighborliness - Treaty of Good-Neighborliness and Friendly Cooperation Between the People's Republic of China and the Russian Federation, 24 julho 2001. [Acedido a 9 de jan. de 2012]. Disponível na Internet: http://www.fmprc.gov.cn/eng/ wjdt/2649/t15771.htm.

Xinhuanet - Russia-China relations at 'unprecedented high': Russian FM, 3 junho 2012. [Acedido a 14 de jun. de 2012]. Disponível na Internet: http://news.xinhuanet.com/ english/china/2012-06/03/c_131628116.htm. 
